\title{
Medical students-as-teachers: a systematic review of peer-assisted teaching during medical school
}

This article was published in the following Dove Press journal:

Advances in Medical Education and Practice

22 June 2011

Number of times this article has been viewed

\section{Tzu-Chieh Yu' \\ Nichola CWilson ${ }^{2}$ \\ Primal P Singh' \\ Daniel P Lemanu' \\ Susan J Hawken ${ }^{3}$ \\ Andrew G Hill'}

'South Auckland Clinical School, University of Auckland, Auckland, New Zealand; ${ }^{2}$ Department of Surgery, University of Auckland, Auckland, New Zealand; ${ }^{3}$ Department of Psychological Medicine, University of Auckland, Auckland, New Zealand
Correspondence: Tzu-Chieh Yu South Auckland Clinical School, University of Auckland Middlemore Hospital

Private Bag 933II, Otahuhu

Auckland 1640, New Zealand

Tel +6492760076

Fax +6492760066

Email wendy.yu@auckland.ac.nz
Introduction: International interest in peer-teaching and peer-assisted learning (PAL) during undergraduate medical programs has grown in recent years, reflected both in literature and in practice. There, remains however, a distinct lack of objective clarity and consensus on the true effectiveness of peer-teaching and its short- and long-term impacts on learning outcomes and clinical practice.

Objective: To summarize and critically appraise evidence presented on peer-teaching effectiveness and its impact on objective learning outcomes of medical students.

Method: A literature search was conducted in four electronic databases. Titles and abstracts were screened and selection was based on strict eligibility criteria after examining full-texts. Two reviewers used a standard review and analysis framework to independently extract data from each study. Discrepancies in opinions were resolved by discussion in consultation with other reviewers. Adapted models of "Kirkpatrick's Levels of Learning" were used to grade the impact size of study outcomes.

Results: From 127 potential titles, 41 were obtained as full-texts, and 19 selected after close examination and group deliberation. Fifteen studies focused on student-learner outcomes and four on student-teacher learning outcomes. Ten studies utilized randomized allocation and the majority of study participants were self-selected volunteers. Written examinations and observed clinical evaluations were common study outcome assessments. Eleven studies provided student-teachers with formal teacher training. Overall, results suggest that peer-teaching, in highly selective contexts, achieves short-term learner outcomes that are comparable with those produced by faculty-based teaching. Furthermore, peer-teaching has beneficial effects on student-teacher learning outcomes.

Conclusions: Peer-teaching in undergraduate medical programs is comparable to conventional teaching when utilized in selected contexts. There is evidence to suggest that participating student-teachers benefit academically and professionally. Long-term effects of peer-teaching during medical school remain poorly understood and future research should aim to address this.

Keywords: peer-teaching, peer-assisted learning, near-peer teaching, medical student, medical school

\section{Introduction}

Interest in peer-teaching (also commonly known as peer-assisted learning or PAL) is growing in the field of medical and allied health education. In theory, advocates of peer-teaching and PAL suggest that its success lies in the fact that peer-teachers and their students share a similar knowledge base and learning experience, otherwise known as "cognitive congruence", which allows the peer-teachers to use language that their learners understand and to explain concepts at an appropriate level. ${ }^{1}$ 
Furthermore, they argue that peer-teachers and student-learners also share a "social congruence" because of their similar social roles, ${ }^{2}$ and this explains why studentlearners feel more at ease with a peer- or near-peer teacher than with a senior clinician. ${ }^{3}$ In undergraduate medical education, Bruffee maintains that peer-teaching serves as a transitional knowledge community that enables medical students to bridge the gap between being a university student and being a clinician. ${ }^{4}$

There is a substantial list of documented qualitative benefits that originate from peer-teaching strategies in the setting of health professional education. These range widely and include enhanced cognitive, psychomotor and affective development of student participants, to economic advantages, and also increased collegial behaviour. ${ }^{5}$ There are also a whole host of subjectively and objectively measured educational benefits.

The identified subjective educational outcomes and student characteristics associated with peer-teaching include student satisfaction, student preference, student learning opportunities, student participation, promotion of student leadership, and student-teacher satisfaction and confidence. ${ }^{5}$ An equally extensive list of objective educational outcomes also exists and these fall into two categories: ${ }^{5}$

- Cognitive: development of clinical reasoning skills and clinical decision-making skills and further development of existing knowledge, reflected by increased academic assessment scores.

- Psychomotor: competence and development of clinical skills demonstrated in mastery of skill and ability to perform, either self-reported or reflected in clinical performance scores.

Since its conception, there have been many attempts by medical educationists to formalize peer-teaching in both undergraduate ${ }^{6-9}$ and postgraduate settings. ${ }^{10-12}$ In the United Kingdom, acknowledgment of peer-teaching and its associated benefits has been formally expressed by the General Medical Council (GMC) whose statement maintains that medical graduates must "be able to demonstrate appropriate teaching skills". ${ }^{13}$

In the United States, interest in peer-teaching and PAL has also been recognized with a survey in 2010 demonstrating that $99(76 \%)$ of the 130 respondent medical schools utilized their medical students in some form of peer-teaching during the medical program. ${ }^{14}$ Furthermore, 57 (44\%) of the schools who responded reported that they also offered their studentteachers a formal medical student-as-teachers (mSAT) training program to support them in their teaching roles. ${ }^{14}$
The enthusiasm for medical students as peer-teachers can also be found in published literature. In a recent systematic review by Pasquinelli and Greenberg, ${ }^{15}$ a total of 39 reports describing mSAT courses were found. They ranged in length from one brief 4-hour session to 12 sessions over 10 months and their reported curricula varied significantly. To summarize these, the review authors grouped them into three major course categories depending on the focus of their curriculum: 1) medical interviewing and physical diagnosis, 2) basic sciences, and 3) faculty development. In addition to curricula that fitted into these categories, the authors also found a smaller number of programs where the mSAT courses functioned to train medical students to fill in the roles of standardized student-learners, medical topic discussion group leaders, standardized patients, and course directors..$^{15}$ Lastly, the systematic review found a global trend in the awareness of peer-teaching during medical school with a total of 7 studies originating from institutions outside of North America.

To assume that these figures represent established mSAT programs is likely an underestimation given that they are dependent on information from survey respondents and from published literature. The interest is therefore, likely to be more widespread than is documented. But despite the mounting theoretical and applied literature focused on peerteaching and related activities in medical schools globally, there remains a distinct lack of objective clarity and consensus about the true effectiveness of peer-teaching and its impact on short- and long-term learning outcomes, learning opportunities, and clinical practice development.

This review aims to summarize and critically appraise evidence of peer-teaching impacting on objective learning outcomes of its participants in undergraduate medical education in order for there to be better clarity on this topic. The learning outcomes of both student-learners and student-teachers will be reviewed and studies utilizing a teacher-training intervention to improve the teaching skills of student-teachers prior to the target peer-teaching activity will also be included. A critical appraisal of study methodologies will accompany the review of study results and a wide-range of different medical teaching activities (classroom didactical teaching, bedside clinical teaching, and procedural skills demonstrations) will be included.

\section{Review objectives}

This review aims to answer the following questions:

1. What are the effects of peer-teaching and PAL activities on the attitudes, knowledge, and learning outcomes of participating students (tutors and tutees) during medical school? 
2. What are the characteristics of these peer-teaching and PAL activities?

3. How have researchers objectively measured the effectiveness and impact of described peer-teaching and PAL activities?

4. What are some important areas for future investigation to advance our understanding of peer-teaching and PAL activities of the undergraduate medical curriculum?

\section{Definitions}

A tremendous diversity of terminologies and definitions currently exists in the literature describing peer-teaching and PAL activities and encounters. To ensure uniformity and clarity, the reviewers have chosen to use the following definition of peer-teaching to delineate the cohort of educational activities focused on by this systematic review: "People of similar social groupings who are not professional teachers helping each other to learn and learning themselves by teaching". ${ }^{16}$

To interpret this definition, the components are individually considered:

1. "Helping each other to learn" broadly encompasses peer participation in virtually all educational activities that are normally performed by professional teachers including production of learning resources and peerevaluation. Although a small number of studies in this review involved student-teachers in curriculum design and development, the focus of the peer-led learning interaction remains on the act of teaching or tutoring.

2. "By teaching" - this component of the definition narrows down the range of educational activities and distinguishes peer-teaching from other types of group activity and cooperative learning, and from initiatives in which medical students act as standardized or simulated patients but do not teach or assess. This component also excludes a list of other peer-based learning activities which do not involve overt peer-teaching such as students presenting their work, engaging in group discussions, practising peer physical examination, and receiving feedback in groups or pairs.

In the context of this review, further clarifications have been included. Medical students are defined as students enrolled in tertiary programs who will eventually qualify as medical doctors. Student-teachers ("tutors") and fellow student-learners ("tutees") are generally students enrolled in the same university institution. "Near-peer teaching" is used to describe more advanced students teaching less advanced students ${ }^{17}$ while "peer-teaching" describes students teaching fellow students within the same educational level and academic year.

\section{Method}

\section{Search strategy and source of papers}

A wide literature search was conducted in October 2010 of four electronic databases: Medline, PubMed, EMBASE and ERIC. Key search terms used were: medical student, undergraduate medical education, peer-teaching, peer group, teaching, tutoring, and peer-assisted learning. All original research articles, reviews, editorials, and essays were retrieved for examination and a bibliography management program (ENDNOTE X3, Thomson Reuters, New York) was used to create a search library.

After screening of a total of 1654 hits (after removal of duplicates), 111 articles were identified as potentially relevant studies based on their titles and abstracts. A hand search through the reference lists of four review articles ${ }^{15,18-20}$ added 16 extra articles to the search results. The reviewers met twice in November 2010 to determine the review inclusion and exclusion criteria, and to select articles for critical appraisal and review. These criteria are listed below.

\section{Inclusion criteria}

1. All study participants are medical students

2. A clinical teaching and learning interaction in any clinical and/or classroom setting

3. A comparative study design using controls (ie, Nonrandomized comparison, Quasi-randomized controlled, or Randomized controlled)

4. Measured learning outcomes in the study include measures beyond that of participant (student-teacher and/or student-learner) satisfaction and self-evaluation. This criterion corresponds to the key aim of this review: to investigate the objective and independent evidence of learning and change

5. If a student teacher-training intervention was utilized, the effectiveness of this intervention (demonstrated as improvements in teaching skills and behavior) was measured by methods other than self-evaluation by the participant, ie, independent and preferably objective outcomes must be measured and reported.

\section{Exclusion criteria}

1. Full-text of article not published in English

2. Studies published prior to 1990 (deemed irrelevant to today's educational environment) 
3. Study results duplicated in separate earlier publications

4. Brief descriptive article.

From 127 potential articles, the inclusion and exclusion criteria were used to select 41 . These were obtained as full-texts for careful and independent examination by the authors. Disagreements amongst the authors were resolved through face-to-face discussions and reasoning as a collective group. The search and selection of papers for this review was completed by February 2011 and a total of 19 studies were selected. Articles were largely excluded on the basis of failure to demonstrate objective study outcomes. One study ${ }^{21}$ was excluded because it was the replication of an earlier study, using the same study methodology but a different cohort of study participants.

\section{Data management techniques Data extraction}

A standardized data extraction and critical appraisal instrument was constructed by reviewers for the sole purpose of this review and it included the following sections and components:

- Study introduction: research objectives and rationale

- Study context: study setting, participant detail, description of the medical program

- Study methods and materials: study design, participant recruitment, study duration and follow-up, resources required, utilization of teacher-training interventions, assessment of objective and subjective study outcomes, methods of statistical analysis

- Dimensions of the peer-teaching interaction:

a. Frequency and duration

b. Group size ${ }^{3}$

c. Distance between tutor and learner ${ }^{3}$

d. Formality of teaching encounter ${ }^{3}$

- Study results: main study findings, attendance and dropout rates

- Impact of peer-teaching interaction: graded using modified models of "Kirkpatrick's Levels of Learning"22

- Study conclusions

- Risks of bias within each study.

Each selected review article was analyzed independently by at least two reviewers (TY, NW, PS, DL, and SH) and data extracted using the instrument described above. In order to gauge study quality, the reviewers considered a variety of factors that could contribute to risks of bias within each study. A critical appraisal framework was structured into the data extraction and review instrument and it asked reviewers to draw conclusions about the validity and reliability of the evidence presented in each article. All collected data were then entered into an electronic data spreadsheet.

\section{Data analysis}

Once the article review process was completed, the collected data from all the reviewers were combined using an electronic data spreadsheet. Discrepancies in opinions between two reviewers were identified and final consensus was reached after face-to-face discussions together with the remaining reviewers.

The "Kirkpatrick's Levels of Learning" model was utilized by the reviewers to form a basic grading scaffold for measuring the "impact size" of educational outcomes from review articles. The original Kirkpatrick's model outlined four levels of educational outcomes. ${ }^{22}$ It was then modified by Freeth et $\mathrm{al}^{23}$ in 2003 for grading the impact size of learning outcomes in medical education and subsequently adopted by the Best Evidence Medical Education (BEME) Collaboration for use in systematic reviews. ${ }^{24}$

Reviewers created two modified adaptations of the Kirkpatrick model to grade the learning outcomes found in this review. Table 1 outlines the first of the modified Kirkpatrick models focused on learning outcomes of the student-learners partaking in peer-teaching and Table 2 outlines a further modified Kirkpatrick model for measuring learning outcomes of the student-teachers facilitating peer-teaching activities. The model used for a particular set of learning outcomes depends on the aim and focus of the study ie, whether it was learner-orientated versus teacherorientated.

\section{Results}

This systematic review includes a total of 19 articles all of which focus on the effectiveness of peer-teaching and peer-assisted learning during medical studies. The teaching interactions described by these studies are a heterogeneous group of educational activities and there was minimal overlap between them. Table 3 summarizes the 15 review studies that focused primarily on peer-teaching learning outcomes of student-learners and Table 4 summarizes the remaining 4 review studies that primarily focused on learning outcomes of the student-teacher participants.

The remaining results section is presented in two parts:

a. Description of study designs, interventions, and outcomes.

b. Methodological quality of studies. 
Table I Modified Kirkpatrick's model for grading impact from peer-teaching on educational outcomes of medical student-learners

\begin{tabular}{|c|c|c|}
\hline Level I & Reaction & $\begin{array}{l}\text { Participants' views of the learning experience, its organization, } \\
\text { presentation, content, teaching methods, and quality of instruction }\end{array}$ \\
\hline Level 2A & Learning - Change in attitudes & $\begin{array}{l}\text { Changes in attitudes or perceptions among participant } \\
\text { groups towards clinical teaching and learning }\end{array}$ \\
\hline Level 2B & $\begin{array}{l}\text { Learning - Modification of knowledge or } \\
\text { skills as a result of participating as a learner }\end{array}$ & $\begin{array}{l}\text { Modification of clinical knowledge: acquisition of concepts, } \\
\text { procedures, and principles } \\
\text { - Modification of clinical skills: acquisition of thinking and } \\
\text { problem-solving, psychomotor, and social skills }\end{array}$ \\
\hline Level 3 & $\begin{array}{l}\text { Behavior - Change in behaviors as a result } \\
\text { of participating as a learner }\end{array}$ & $\begin{array}{l}\text { Documents the transfer of newly acquired clinical knowledge and skills to } \\
\text { practice or the willingness of participants to apply the knowledge and skills }\end{array}$ \\
\hline Level 4A & $\begin{array}{l}\text { Results - Change in the system or } \\
\text { organizational practice }\end{array}$ & $\begin{array}{l}\text { Refers to wider changes in the organization attributable to } \\
\text { the educational program }\end{array}$ \\
\hline Level 4B & Results - Change in patient health outcomes & $\begin{array}{l}\text { Refers to improvement in patient care and patient outcomes as a } \\
\text { direct result of participation as a learner }\end{array}$ \\
\hline
\end{tabular}

\section{Description of study designs, interventions, and outcomes}

\section{Study settings}

The studies in this review were scattered across all five continents with Europe being the most commonly represented. A total of six studies ${ }^{6,25-28}$ were set in the United Kingdom and they originated from four different educational institutions. Germany and the United States were the next two countries most commonly represented, each with four studies originating from them.

All studies were set in tertiary educational institutions with committed medical programs. The majority of studies did not provide readers with descriptions of these programs. Four studies ${ }^{6,28-30}$ described the total duration of their medical programs and these were all 6 years in duration. Three studies $^{25,31,32}$ described their medical programs as comprising of pre-clinical and clinical phases but provided no further details clarifying class sizes, duration of program, structure of the curriculum, etc.

\section{Study participants}

The seniority of participating student-teachers ranged from Year 2 to final-year (Year 6) medical students and participating student-learners ranged from Years 1 to 5. Three studies did not report the seniority of their research participants. ${ }^{25,32,33}$ One of these studies, ${ }^{25}$ simply made a distinction between "senior" and "junior" medical students.

After considering the study participants, the majority of the studies, examined "near-peer" teaching activities although this term was not commonly utilized by study authors. True "peerteaching", in comparison, was described by only five of the studies. ${ }^{29,34-37}$ Although it was not possible to apply these definitions to Sobral's study ${ }^{32}$ because information on seniority of participating students was not given, the student-led problem-based

Table 2 Modified Kirkpatrick's model for grading impact from peer-teaching on educational outcomes of medical student-teachers

\begin{tabular}{ll}
\hline Level I & Reaction \\
Level 2A & Learning - Change in attitudes \\
Level 2B & $\begin{array}{l}\text { Learning - Modification of knowledge or } \\
\text { skills as a result of participating as a teacher }\end{array}$
\end{tabular}

Level 3 Behavior - Change in behaviors as a result of participating as a teacher

Level 4A Results - Change in the system or organizational practice

Level 4B Results - Change in patient health outcomes
Participants' views of the teaching experience, its organization, presentation, content, teaching methods, and quality of instruction Changes in attitudes or perceptions among participant groups towards clinical teaching and learning

- Modification of teaching knowledge: acquisition of concepts, procedures, and principles

- Modification of teaching and tutoring skills: acquisition of thinking and problem-solving, psychomotor, and social skills

Documents the transfer of newly acquired teaching knowledge and skills to practice or willingness of participants to apply the teaching knowledge and skills

Refers to wider changes in the organization attributable to the educational program

Refers to improvement in patient care and patient outcomes as a direct result of participation as a teacher 


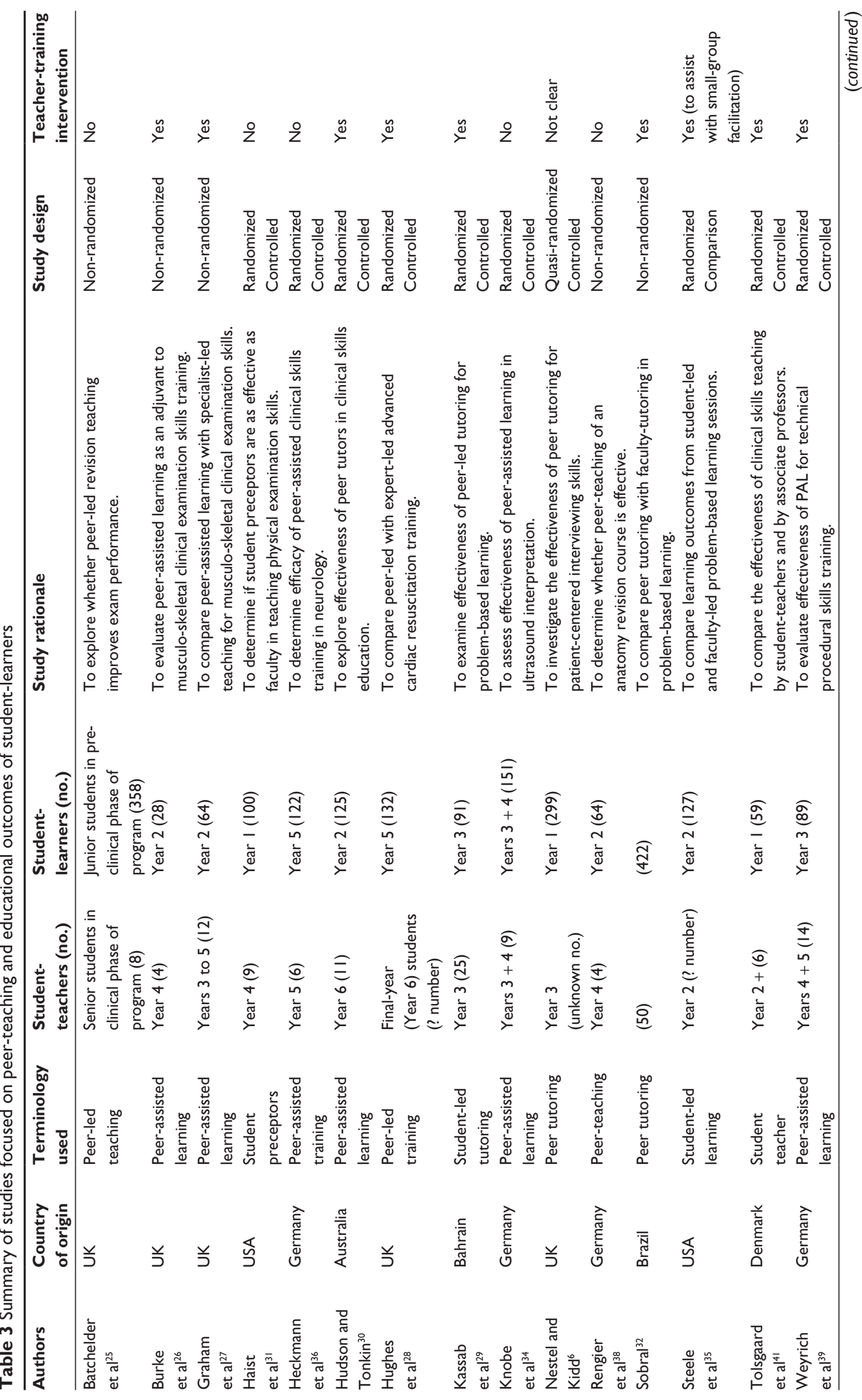




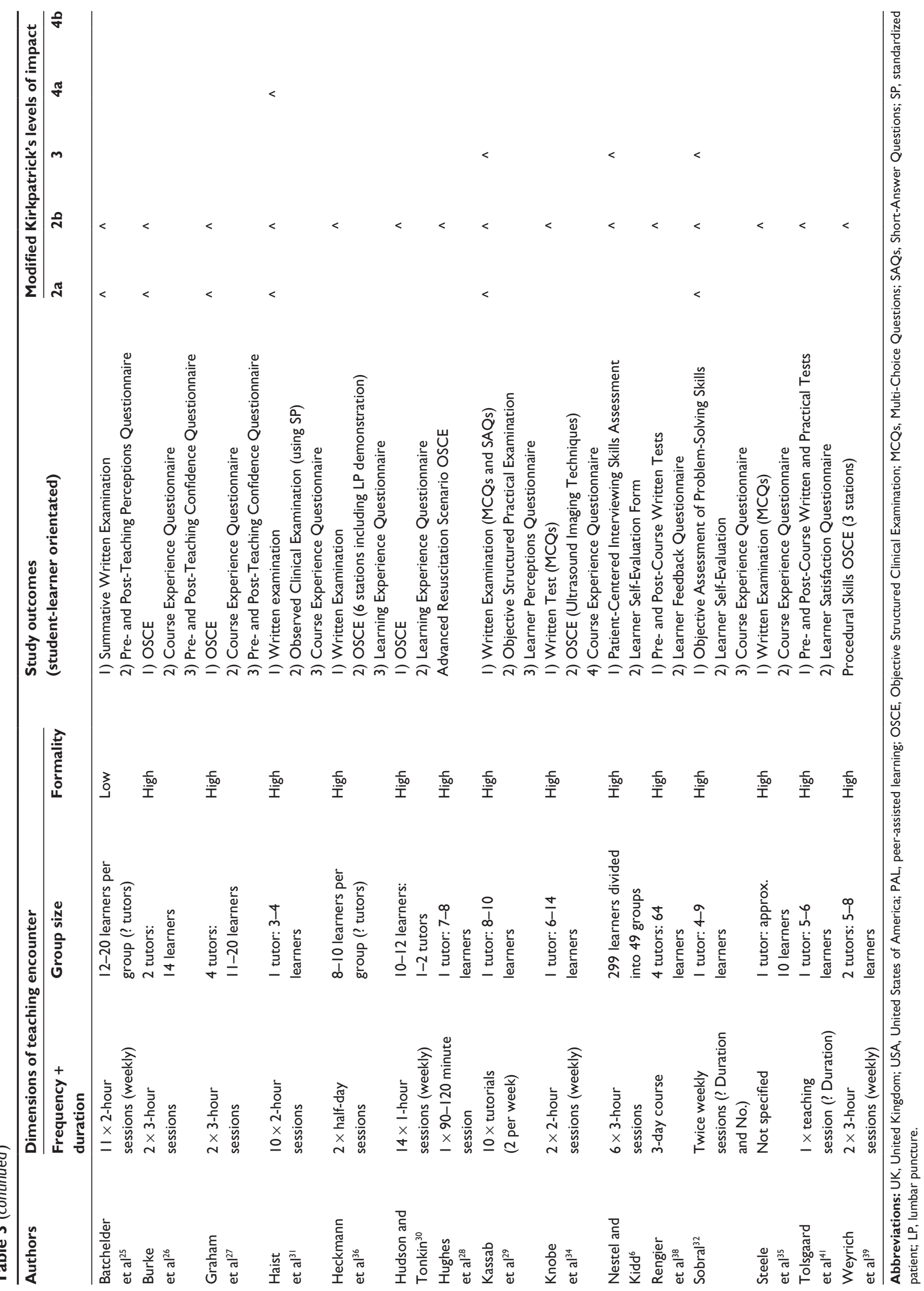


Table 4 Summary of studies focused on peer-teaching and educational outcomes of student-teachers

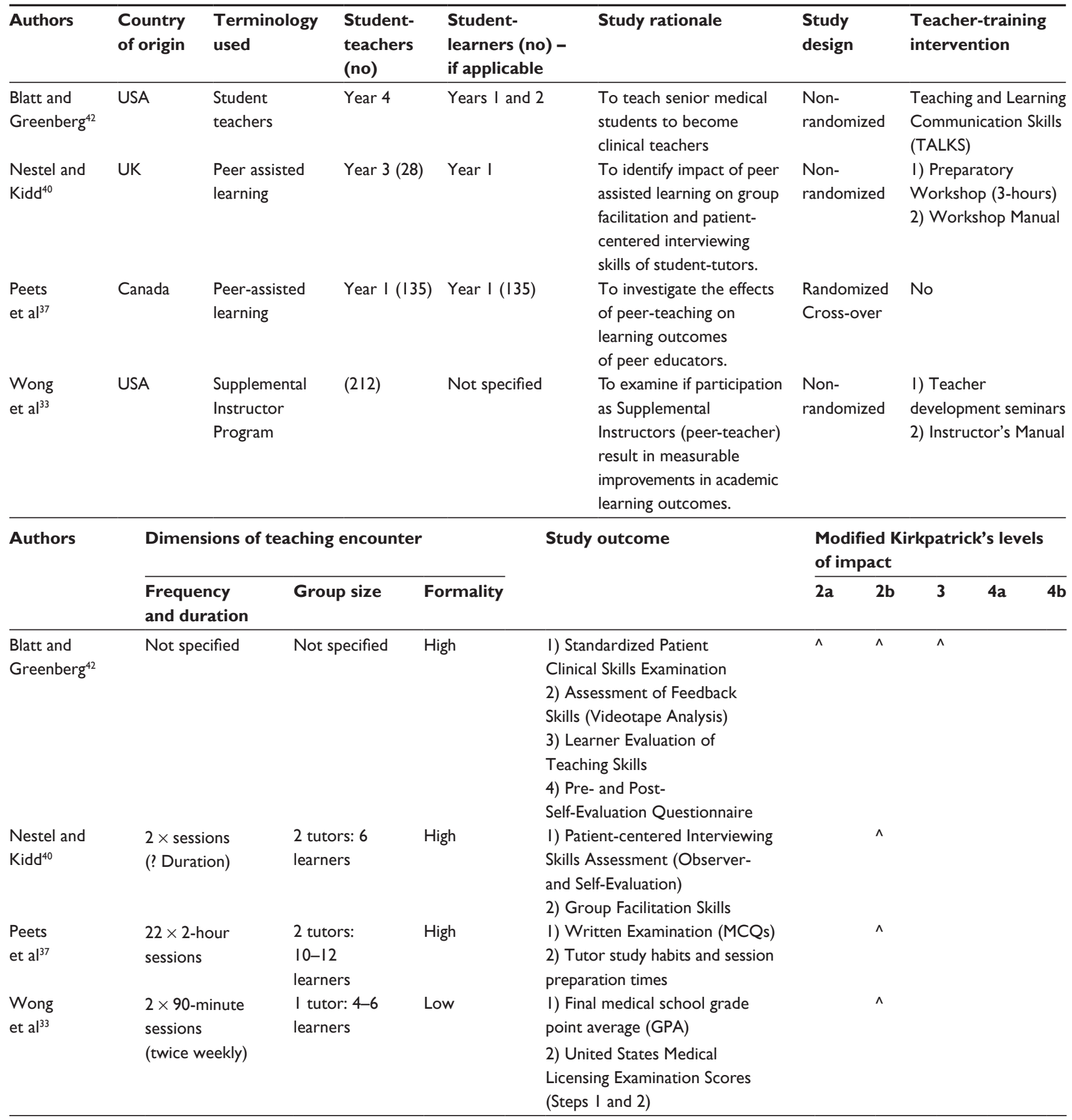

Abbreviations: UK, United Kingdom; USA, United States of America; MCQs, Multi-Choice Questions.

learning (PBL) sessions under investigation were described as being facilitated and directed by student-tutors "who had taken the $[\mathrm{PBL}]$ course one or two terms before". This suggests that it was likely a true "peer-teaching" activity.

As pointed out in Sobral's study, any previous participation in or experience with the teaching material and content under investigation as a novice learner is logically an important factor to consider when selecting a group of peer-teaching tutors and instructors. The majority of the studies describing near-peer teaching activities involved student-teachers who had previously participated in the same teaching interaction as a learner and there were only three exceptions to this. Each of these studies examined newly introduced near-peer teaching activities where the student-teachers had no previous experience with its content, structure, and instructional methods. ${ }^{25,28,38}$ 
Batchelder et $\mathrm{al}^{25}$ described a near-peer revision program to prepare junior students for a high-stake pre-clinical summative written examination while Rengier et $a l^{38}$ described the impact of a peer-led anatomy revision course, designed and conducted by senior medical students, on the performance of junior students in the national anatomy written examination. All peer-teachers acting as revision course tutors in the latter study had two years of experience as undergraduate instructors in gross anatomy laboratories and had also given revision lectures that accompanied anatomy laboratory sessions where they were under the supervision of senior faculty members.

The assessment of previous teaching experience in student-teachers was only described by two other studies. ${ }^{34,39}$ One of these studies compared the effectiveness of clinical skills teaching by peer-tutors and by experienced faculty staff. The peer-tutors were selected on the basis of previous experience as clinical teachers, and motivation levels. ${ }^{39}$

\section{Focus of peer-teaching}

The diversity of topics focused on by peer-teaching interactions included in this systematic review reflects the variety of different educational activities where peer-teaching and PAL have been attempted. A total of seven studies investigated the effectiveness of peer-teaching in clinical skills training ranging from basic history-taking and physical examination skills $^{26,27,30,31}$ to more specific competencies such as patientcentered interviewing skills. ${ }^{6,40}$ In a minority of studies, peer-teachers provided instruction on more than one set of skills. For example, in the study conducted by Heckmann et al, ${ }^{36}$ investigators described peer-assisted training during a one-week neurology clerkship where student-teachers taught peers, in the same class, physical examination skills focused on the neurological system and procedural skills for performing a lumbar puncture.

Another common focus was the effectiveness of peerteaching during small-group problem-based learning (PBL) interactions. Student-teachers were utilized to lead and direct PBL group discussions ${ }^{29,32,35}$ and other clinical case-based presentation sessions ${ }^{37}$ The remaining studies in this review focused on a variety of different peer-teaching activities including procedural skills training, ${ }^{39,41}$ anatomy revision, ${ }^{38}$ basic medical sciences tutoring, ${ }^{33}$ training in ultrasound imaging skills, ${ }^{34}$ facilitating clinical examinations as standardized patients, ${ }^{42}$ assisting with revision of the curriculum,,${ }^{25}$ and demonstration of advanced cardiac resuscitation skills. ${ }^{28}$

In addition to instructional teaching and tutoring, three of the studies ${ }^{25,28,38}$ also described student-teachers participating in curriculum design. For example, Batchelder et $\mathrm{a}^{25}$ investigated whether a revision program developed and delivered by senior medical students would improve the performance of junior students in a summative written examination while Rengier et $\mathrm{a}^{38}$ investigated whether a revision anatomy course designed and implemented by senior students would benefit junior students. Both of these studies allowed student-teachers total autonomy to decide on the aims, material contents, and delivery methods for the teaching activity. By comparison, investigators of the third study set specific goals for the peer-teaching activity under examination. Hughes et $\mathrm{al}^{28}$ investigated the effectiveness of final-year medical students as instructors for an advanced cardiac resuscitation course where they had also devised the course format, content, and structure but were given specific learning objectives and goals.

\section{Dimensions of teaching}

Four dimensions of peer-teaching were used to describe and categorize the teaching interactions that occurred in the reviewed studies: 1) frequency and duration of sessions, 2) distance between student-teachers and student-learners (difference in seniority), 3) group size ${ }^{3}$ and teacher-student ratio, and 4) level of formality during the teaching encounter. ${ }^{3}$ While the first three dimensions are objective descriptions, the last dimension was a subjective judgment made by the reviewers. Tables 3 and 4 summarize the dimensions of teaching for each of the studies in this review.

The frequency and duration of peer-teaching encounters were not always reported clearly. The reviewers found that the frequencies ranged from twice weekly to once weekly and the duration of individual sessions ranged from one hour to half-a-day. The size of student-learner groups was generally small across all the studies although this information was not always available.

In general, student-teachers utilized by review studies were incorporated into the medical program as obligatory instructors and therefore the formality of teaching encounters was high. In comparison, formality was subjectively considered to be low when senior students led extra-curricular teaching activities to help more junior students prepare for classes or tests, and this was the case in only two of the reviewed studies..$^{25,33}$

\section{Teacher-training interventions}

Eleven of the 19 studies reported the provision of formal teacher-training for participating student-teachers. Details of these courses were, however, generally not well described. 
Only three studies provided descriptions of the course structure, content, and delivery method.

The first of these studies was conducted by Blatt and Greenberg ${ }^{42}$ to investigate the multi-level impact of a teachertraining elective program for senior medical students. The TALKS (Teaching and Learning Communication Skills) elective is an optional program that aims to train senior medical students to become more effective clinical teachers. It had three components: 1) Six 2.5-hour workshops on education topics with multiple, graduated practice opportunities, 2) a practicum that involved assisting faculty with teaching of physical diagnosis skills to first and second year medical students, and 3) role-playing standardized patients during observed clinical examinations for first and second year students.

Weyrich et $\mathrm{al}^{39}$ evaluated the effectiveness of studentteachers employed as procedural skills demonstrators and instructors in a clinical skills learning laboratory. All studentteachers (years 4 and 5 students) received teacher training and preparation for their instructor roles and this included: 1) two 3-hour consultant-facilitated tutor training sessions, 2) two 4-hour standardized student-tutor didactic seminars divided into five topic modules (how to deliver a precise explanation, Peyton's four-step teaching method, how to cope with difficult teaching situations, non-announced ad hoc teaching scenarios as practice exercises, a 7-minute personal presentation by each student with video coaching).

Wong et $\mathrm{l}^{33}$ investigated the impact of peer-teaching on the formal academic learning outcomes of student-teachers. The Supplemental Instructor (SI) program paired senior student tutors with small groups of junior students who received basic sciences tutoring throughout the course of an academic year. These SI tutors underwent an active training program and received an instructor's manual outlining pedagogical strategies in small-group instruction and procedural issues. They also participated in annual teacher development seminars focused on the core pedagogical elements of small-group teaching and emphasized facilitation of inquiry, student-tostudent dialog and explanation, anticipation of examination style question, and presentation of material amenable to a variety of student learning styles.

\section{Study outcomes measured}

Studies frequently assessed multiple outcomes from peerteaching and PAL activities and Tables 3 and 4 summarize the main learning outcomes in each of the 19 studies. Written examinations and observed clinical examinations were the most common forms of objective assessment used by investigators to evaluate learning outcomes of studentlearners. Written examinations on theory and knowledge ranged from individual course-based evaluations to national standard evaluations such as a nation-wide anatomy examination $^{38}$ and the US Medical Licensing Examinations. ${ }^{33}$ Investigators generally provided brief descriptions of written and directly-observed clinical evaluations and this allowed readers to consider the appropriateness of each evaluation in the context of the study.

In addition to curriculum-based evaluations such as written examinations and objective structured clinical examinations (OSCEs), study investigators also measured a range of other objective outcomes to try to demonstrate the total impact of target peer-teaching activities. For example, besides obtaining written examination and OSCE results, Knobe et $\mathrm{al}^{34}$ also measured the time student-learners needed to generate a reliable ultrasound image and the quality of these images in order to establish the effectiveness of peer-teaching for coaching shoulder ultrasound imaging techniques. Blatt and Greenberg ${ }^{42}$ provide another example by using an interaction analysis methodology to evaluate the videotaped teaching performances of student-teachers providing feedback to their learners.

There were also a variety of different subjective outcomes measured in the studies. Many different questionnaires were created or adopted for the evaluation of student-teacher and student-learner reactions, perceptions, attitudes, satisfaction, and confidence levels. Self-evaluation by student-learners was also a form of subjective outcome measured in several studies, ${ }^{6,29,32}$ as was self-evaluation by student-teachers of their teaching performance and gains in teaching skills. ${ }^{36,40}$ Lastly, a number of studies also asked student-learners to subjectively rate the teaching performance and skills of participating teachers (student- and faculty-teachers) and the overall quality of their teaching..$^{29,31,34,42}$

\section{Study results}

Results illustrating the effectiveness and impact of peerteaching and PAL activities can be broadly grouped into 4 categories. The largest category consists of results from studies that compared the effectiveness of peer-teaching and conventional teaching where instructions were given by faculty members, trained expert instructors, clinicians, or post-graduate tutors. A total of 12 studies focused on this objective and, apart from two studies, the majority were able to demonstrate equal student learning outcomes.

The first exception was the study conducted by Knobe et al, ${ }^{34}$ which found that, despite comparable written 
examination and OSCE scores, student-learners in the faculty-led ultrasound training group required less time to produce a desirable ultrasound image compared to the peer-led training group. The second study was conducted by Tolsgaard et $\mathrm{al}^{41}$ and it observed that the bladder catheterization procedural skills of student-learners in the student-led demonstration group was significantly better compared to those of student-learners taught by Associate Professors.

The second category consisted of results from four studies. ${ }^{25,26,38,39}$ These studies simply set out to demonstrate that peer-teaching as an educational intervention has supplementary benefits for learner outcomes and they did this by comparing learning outcomes of students in peer-taught groups with those in control (no peer-teaching) groups. Two studies ${ }^{25,38}$ found that peer-teaching did not impact the learning outcomes of student-learners while the other two studies demonstrated that peer-teaching in musculoskeletal clinical examination skills can improve student-learner passrates in an end-of-year OSCE, ${ }^{26}$ and also improves OSCE performance scores when used to train student-learners in a skills training laboratory. ${ }^{39}$

The third category of results focused on learning outcomes of peer-teachers. This category contains results from five studies ${ }^{33,34,37,40,42}$ that all consistently agreed on the beneficial effects of peer-teaching on student-teacher outcomes. The studies demonstrated this either by comparing student-teacher outcomes with those from a control group ${ }^{33,37,40,42}$ or from a group of their student-learners. ${ }^{34}$ An exception to this overall finding was the study by Nestel and $\mathrm{Kidd}^{40}$ which failed to find any significant improvements in the interviewing skills of student-teachers after participation in a peer-facilitated skills course. Their interviewing skills were rated pre- and post- the peer-teaching activity by trained standardized patients and comparison was also made with a control group of fellow students who did not participate in peer-teaching.

The fourth results category grouped together the qualitative results from reviewed studies. Although results in this category did not help to objectively demonstrate the effectiveness of peer-teaching, they offered insight into the experiences, reflections, and concerns of participating student-learners and student-teachers. For example, besides demonstrating objective and academic learning outcomes from peer-led PBL-based small group tutoring sessions, Kassab et al ${ }^{29}$ also sought to explore the perceptions of student-learners using an open-ended questionnaire. They were able to suggest that the strengths of peer-teaching lay in the fact that student-tutors were better at assessing student-learner knowledge and understanding their learn- ing difficulties. Student-learners also appreciated the more relaxed learning environment created by student-tutors. The downside to these observations was student-learners felt that peer-led sessions risked discussion difficulties during case problem analysis and peer-led tutoring was reducing their contact time with faculty. Student-teachers' competency was also questioned by student-learners in two other studies ${ }^{34,36}$ while the observation that peer-led small groups functioned at a more relaxed and co-operative level was echoed in yet another study. ${ }^{35}$

\section{Kirkpatrick's levels of impact}

The highest level of impact found in this review was Level 4a. It was achieved in a study that investigated the effectiveness of Year 4 student-teachers as tutors in the Year 1 Physical Examination Module. ${ }^{31}$ The authors reported that the success of this near peer-teaching activity has led to changes at an organizational level with the initial plans to formally incorporate peer-teaching into the Year One curriculum.

Tables 3 and 4 summarize the levels of impact achieved by each study in this review. Not conveyed in these tables are the peer-teacher performance and effectiveness ratings awarded by student-learners reported in learner-focused studies. Teacher performance ratings are considered Level 3 outcomes because they related to teaching behavior of student-teachers and examples of these ratings can be found in the studies by Kassab et a ${ }^{29}$ and Tolsgaard et al. ${ }^{41}$

\section{Methodological quality of studies}

\section{Study research rationale}

A variety of different reasons were used by study authors to explain why particular peer-teaching activities were developed, implemented, and evaluated. Frequently, individual studies referred to multiple motivating factors. The reviewers have simplified these study rationales into three categories: 1) theory-based with support from literature, 2) problembased and driven by practicality, and 3) founded on recommendations from professional accrediting bodies such as the General Medical Council in the United Kingdom. ${ }^{25,40}$

Of these three categories, the most frequently encountered justifications were those with a practical basis. A total of nine studies ${ }^{6,25,28,30,31,34,36,40,41}$ linked their peer-teaching initiatives to a practical need for alternative undergraduate teaching methods to combat increasing student numbers and mounting pressures on faculty-based resources. Logically, these studies all aimed to demonstrate equivalence in student-learner outcomes when peer-teaching was used in place of conventional and traditional teaching methods. 
The conventional teachers in these studies included senior faculty academics, postgraduate course tutors, specialist resuscitation skills demonstrators (from both medical and nursing backgrounds), and physiotherapists.

\section{Study design}

Ten studies used randomized participant allocation in this review while there was one study that used quasi-randomized allocation and eight that used non-randomized allocation methods. In general, randomization methods were not described by authors and replication was impossible. The study with quasi-randomization was achieved using alphabetical allocation according to student-learner surnames. ${ }^{6}$ Study sample sizes varied vastly and only three studies performed a priori power calculations to ensure adequate sample populations. ${ }^{28,38,39}$

The majority of studies adopted short follow-up durations (time from peer-teaching activity to evaluation of participant learning outcomes). Immediate evaluation of student learning outcomes at the completion of peerteaching activities typically occurred in studies that focused on procedural and technical skills training. ${ }^{28,39,41}$ It also occurred in the study conducted by Heckmann et al, ${ }^{36}$ where authors evaluated student-learner outcomes immediately upon their completion of a near-peer taught neurology clerkship.

Follow-up at the end of an academic year (which frequently corresponded with the completion of the peer-led teaching activity) was a relatively common strategy found in four studies. ${ }^{25-27,29}$ The longest follow-up duration was undertaken by Wong et $\mathrm{al}^{33}$ who evaluated the academic performances of student-teachers at the completion of their medical degree, 4 years from the time they began participating in the Supplemental Instructor's program, a peer-led tutoring system where senior students lectured juniors on basic science topics.

\section{Risks of bias}

Risks of bias found in this review can be divided into four types.

\section{Participant sampling and selection bias}

Participant recruitment strategies by studies in this review are divided into two groups: those for recruitment of student-teachers and those for student-learners. Self-selected volunteers made up the majority of study participants in this review and bias associated with this created problems when reviewers were attempting to determine causation and evaluate the effectiveness of interventional peer-teaching programs.

With the exception of four studies, recruitment of student-teachers by study authors was based on voluntary self-selection. Limited information was given on how student-teachers were approached and how student-teacher positions were advertised. Some study investigators recruited on a "first come, first served" 41 philosophy and many did not set any pre-requisite selection criteria, choosing to extend an open invitation to the whole target group. . $^{6,26,40}$

In comparison, a small number of studies limited studentteacher recruitment by setting certain pre-requisite conditions. Some of the conditions were broad while others were very specific. For example, Weyrich et $\mathrm{al}^{39}$ selected studentteachers on the basis of previous teaching experience and selfmotivation levels which are both loosely-defined measures, while Haist et $\mathrm{al}^{31}$ specifically selected only senior students who achieved Grade A results and GPA scores of $\geq 3.4$.

A final alternative method of recruiting volunteer student-teachers was found in two studies where participants were previous or current students enrolled in a medical education-related course or selective option. ${ }^{28,42}$ For example, Blatt and Greenberg ${ }^{42}$ recruited participants in the TALKS program in order to determine its impact on communication skills of senior medical students. This is a selective option open to all Year 4 students at George Washington University School of Medicine to determine whether partaking in this program advanced communication skills, investigators compared TALKS participants with non-participating controls whose manner of recruitment was not specified.

Four studies ${ }^{29,34,35,37}$ recruited participants as entire class cohorts and then assigned the student-teacher and studentlearner roles to individuals. During two of the studies, ${ }^{34,37}$ student-teachers retained their teacher's role for the total duration of the peer-teaching program while during the remaining two studies, the peer-teacher role was rotated around within tutorial groups and differed for different sessions. The student-teachers were either randomly selected ${ }^{35}$ or elected by student-learners. ${ }^{29}$

Participating student-learners in this review belonged exclusively to one of two categories: self-selected volunteers or automatically enrolled members of entire class cohorts. Recruitment strategies used to attract voluntary student-learners were generally not described so that reviewers only found two studies that explained this. In the first study, investigators placed advertisements in the school magazine, ${ }^{41}$ and in the second study, participating student-teachers were tasked with recruiting their own 
student-learners and they did this using emails and advertising posters. $^{26}$

\section{Outcome assessment bias}

This review is focused mainly on the objective learning outcomes from peer-teaching and PAL activities and therefore, this section will concentrate mainly on the risks of bias when objective assessment and measurement tools were utilized by study authors.

As mentioned earlier, objective structured clinical examinations (OSCEs) and other variations of directly-observed clinical evaluations were commonly found in this review. A total of ten studies used this form of evaluation to assess learning outcomes of student-learners but, given how variable these evaluations can be, few authors actually provided adequate descriptions of the evaluations they utilized to assess, what was often, the study's primary outcome. The use of checklist-based marking schedules during observed clinical evaluations was popular and so was employing blinded and independent assessors in order to maintain objectivity and standardization. Out of these ten studies, $\operatorname{six}^{26-28,36,39,41}$ utilized blinded assessors who directly observed clinical performances of participating student-learners.

Professionally trained standardized patients (SPs) were regularly encountered in this review and utilized to facilitate clinical evaluations and also to simultaneously evaluate study participants (student-teachers and -learners). A total of six studies employed SPs during study outcome evaluation and in four studies, ${ }^{6,31,40,42}$ the SPs were also trained to assess study participants. The study by Haist et al ${ }^{31}$ illustrates the level of competency achievable by professional SPs. The authors of this study trained SPs to complete a 213-item evaluation checklist scoring Year 1 medical students on history-taking and physical examination skills.

The psychometric properties of various outcome evaluation tools were also rarely mentioned by study authors. Reviewers were only reassured of the validity and reliability of evaluation instruments by authors of three studies. During two of these studies, Nestel and Kidd set out to investigate the impact of peer-led interviewing skills training on patientcentered interviewing skills of both participating studentteachers ${ }^{40}$ and student-learners. ${ }^{6}$ The inter-rater reliabilities of "interview rating scales" used in both studies were provided and authors also made reference to their face and content validity. In the third study, Tolsgaard et $\mathrm{al}^{41}$ conducted an initial pilot study to determine the inter-rater reliability of an evaluation grading checklist before it was subsequently used to evaluate procedural skills in participating student-learners.

\section{Reporting bias}

The reporting of study methodology was variable and this limited the extent to which reviewers could critically appraise study designs. Throughout this review, the reviewers generally defined "insufficient reporting" as situations when the study methodology was not described in enough detail for replication. Despite the strict review selection criteria, poor reporting was evident in some studies and the reviewers frequently had to assume that certain quality-control initiatives were not deployed because they were not reported by study authors. There were, however, occasional examples of accurate reporting such as the use of the CONSORT statement ${ }^{43}$ diagram by Hughes et $\mathrm{al}^{28}$ to outline the course of participant recruitment.

\section{Other risks of bias}

There is one other contributing factor to the risk of bias that the reviewers wish to highlight. Formally rewarding studentteachers with financial compensation was described by three studies in this review. During two of these studies, ${ }^{39,41}$ senior students were formally employed as regular assistant tutors and instructors and in the remaining study, ${ }^{31}$ student-teachers were paid an honorarium and presented with an engraved plaque for their participation. Financial and gratitude teaching incentives can introduce bias at several stages of an evaluation study, particularly during student-teacher recruitment.

\section{Discussion}

This systematic review identified a total of 19 studies investigating the impact of peer-teaching activities during medical school on objective learning outcomes of student participants. The review's conclusions are drawn from their results and from a critical appraisal of their methodologies.

Firstly, investigators have integrated peer-teaching into a wide variety of different classroom and bedside teaching activities. The variety of peer-teaching encounters embraced by the studies ranged from peer-led PBL small-group discussions, to peer-devised revision tutorials in anatomy and basic sciences, and peers demonstrating clinical and procedural skills and training one another in complex cardiac resuscitation skills. The degree of heterogeneity amongst the studies meant that direct comparison was unfeasible.

Secondly, study authors have used a mixture of study investigative designs and methodologies to demonstrate and determine the educational impact of peer-teaching activities during their medical program. Overall, randomized or quasi-randomized study designs were relatively 
common and evaluated objective outcome measures were appropriate.

Thirdly, the results of these studies reliably indicate that peer-teaching and PAL activities, implemented in a highly selective context, can achieve equivalent student learning outcomes when compared to the conventional teaching methods used in an undergraduate medical curriculum. This suggests that peer-teaching and PAL initiatives may be a solution to the global trend of increasing medical student numbers and shortage in faculty resources. From the results of this review, it is also possible to conclude that peer-teaching has beneficial effects on the learning outcomes of participating student-teachers.

Having drawn the above conclusions, there are several important issues that the reviewers intend to discuss, including the limitations of this review. The first concerns the collection of underlying research rationale and motives found in the studies. Published accounts of medical students serving as teachers during medical school first began to appear in the 1990 s. ${ }^{44}$ Since then, there has been a gradual growing appreciation, internationally and across specialty disciplines, for the need to aid medical graduates in developing the skills, attitudes and practices of competent teachers. ${ }^{13,45-47}$ This trend has been, in part, driven by a number of theoretical motives that are student-centered. To rationalize why a considerable amount of effort has been invested into this area of medical education, Dandavino et $\mathrm{al}^{19}$ recently summarized the four reoccurring theories in current literature:

1. Medical students with a better understanding of teaching and learning principles may become better learners.

2. Because teaching is an essential aspect of physicianpatient interaction, medical students may become more effective communicators as a result of such training.

3. Medical students are future residents, consultants, and faculty members who will have formal teaching roles.

4. Exposure to teaching principles, skills, and techniques should be in a sequential manner during the education of a physician, starting in medical school and continuing throughout postgraduate education and into practice.

In considering these theoretical motives, it would seem that the driving forces for peer-teaching during medical school "in theory" are different to those operating "in practice". A majority of the studies in this review were motivated by the need for an alternate yet comparable supply of teachers to combat a shortage of faculty teaching staff and increasing medical student numbers, and so authors had very pragmatic approaches to the design, implementation, and evaluation of peer-teaching activities. Accordingly, they have demonstrated that peer-teachers can provide teaching assistance for faculty and contribute to curriculum development. In comparison, only a small number of studies in this review set out to demonstrate the validity of proposed learning theories advocating peer-teaching. Encouragingly, their results suggest that peer-teaching does strengthen the student-teacher's own knowledge and skills so learning is indeed reinforced by teaching the material to others. ${ }^{16}$

Another principle to bear in mind when reviewing literature concerning this topic is the fact that there is currently no consensus on what teaching competencies are expected of medical students. Since the establishment of competencies is a natural step in the educational evolution of an innovation, a competency framework would provide medical educationists with a common set of goals to unite their research efforts. This lack of consensus is reflected by the results of this review in several ways: the shortage of studies that measured teaching competencies of student-teachers, the diversity of peerteaching and PAL activities outlined, and the large number of experimental settings in which peer-teaching was trialed.

The reviewers wish to point out several limitations to this systematic review. They derived mainly from poor reporting by study authors and from bias risks as a consequence of study design and methodologies. As mentioned in this review, poor and insufficient reporting of study procedures limited the extent to which reviewers could reliably draw conclusions about the impact and effectiveness of target peer-teaching activities. To improve the quality of future studies, the reviewers strongly recommend that investigators reporting on peer-teaching activities and encounters describe these using Topping's "teaching dimensions". ${ }^{16}$ By using the dimensions as a standardized reporting framework, future research into peer-teaching can be accurately communicated, compared, and replicated.

Self-selection bias was prevalent amongst the studies in this review and it is not an uncommon experimental weakness in medical education literature. In fact, self-selection bias is a major research problem in the social sciences. ${ }^{48}$ Although an ethically-sound solution may not exist, it is important to contemplate the bias and consequences associated with self-selected participants when designing and implementing peer-teaching activities in a medical education setting. In the early stages of piloting a peer-teaching activity, it may, in fact, be favorable for individuals to self-select into studentteacher roles given that some intrinsic characteristics such as confidence, motivation, and ability to articulate ideas and expressions, are all helpful with the transitioning from fellow student to peer-teacher. In the later stages of implementing a peer-teaching program, establishment of its acceptability 
and feasibility may require participation by student-teachers who are not self-selected.

Another review limitation lies in its sole focus on objective learning outcomes from peer-teaching activities. Due to the questionable correlation between personally reported self-confidence and objective performance measures, selfconfidence ratings cannot be considered reliable data for determining learning progress and they were therefore, ignored by the reviewers. ${ }^{49}$ But self-evaluation, experience ratings, and individual reflection should not be overlooked because they are often also valuable and insightful outcomes from peer-teaching encounters.

A number of subjective outcomes were found amongst the studies in this review including the degree to which studentteachers were able to establish stimulating and unique learning environments, ${ }^{30}$ their ability to facilitate open and more relaxed small-group PBL discussions, their capacity to better understand learning difficulties faced by student-learners, ${ }^{29}$ and their aptitude for making teaching sessions more enjoyable. ${ }^{34}$ Although the association between these factors and formal academic learning outcomes may be difficult to establish, they help to indicate student support, co-operation, and satisfaction, and may in fact determine the sustainability and eventual success of a peer-teaching program.

This review has uncovered a number of gaps in our current understanding of peer-teaching during medical school and the reviewers would like to propose that these become the focus for future investigations. One of the key issues is a lack of evidence demonstrating the possible long-term impacts of peer-teaching. What is currently available is limited by short follow-up durations, and without information on the enduring impact of undergraduate peer-teaching activities, it is difficult to argue that medical school is the ideal time to prepare medical students for their eventual teaching roles. ${ }^{14}$ Linked to this shortcoming in our understanding of peer-teaching is how little we know about the impact of peer-teaching on non-academic aspects of medical education such as practicing life-long learning, decision-making processes, leadership skills, affective development, professionalism, and future attitudes towards clinical teaching and learning as residents and senior clinicians.

\section{Conclusion}

From the results of this systematic review, it can be concluded that the impact of peer-teaching on objective learning outcomes of medical students appears to be equivalent to that of conventional faculty-led teaching in selected contexts. Results also suggest that there are potential learning benefits for student-teachers who participate in peer-teaching and PAL activities, and careful consideration needs to be given to the ways in which student-teachers are supported before, during and after the peer-teaching encounter. Due to short study follow-up durations, it is currently not possible to draw any conclusions about the long-term enduring effects of peer-teaching during medical school.

\section{Disclosure}

The authors report no conflicts of interest in this work.

\section{References}

1. Cornwall MG. Students as Teachers: Peer Teaching in Higher Education Amsterdam: Centrum Onderzoek Wetenschappelijk Onderwijs; 1980.

2. Schmidt HG, Moust JH. What makes a tutor effective? A structuralequations modeling approach to learning in problem-based curricula. Acad Med. 1995;70(8):708-714.

3. Ten Cate O, Durning S. Dimensions and psychology of peer teaching in medical education. Med Teach. 2007;29(6):546-552.

4. Bruffee KA. Collaborative Learning: Higher Education, Interdependence, and the Authority of Knowledge. 2nd ed. Baltimore: The Johns Hopkins University Press; 1999.

5. Secomb J. A systematic review of peer teaching and learning in clinical education. J Clin Nurs. 2008;17(6):703-716.

6. Nestel D, Kidd J. Peer tutoring in patient-centred interviewing skills: experience of a project for first-year students. Med Teach. 2003;25(4): 398-403.

7. Solomon P, Crowe J. Perceptions of student peer tutors in a problembased learning programme. Med Teach. 2001;23(2):181-186.

8. Morris D, Turnbull P. Using student nurses as teachers in inquiry-based learning. $J A d v$ Nurs. 2004;45(2):136-144.

9. Ross MT, Cummings AD. Peer assisted learning. In: Harden RM, Dent JA, editors. A Practical Guide for Medical Teachers. 2nd ed. Edinburgh, UK: Elsevier; 2005.

10. Rogers DA, Regehr G, Gelula M, Yeh KA, Howdieshell TR, Webb W. Peer teaching and computer-assisted learning: An effective combination for surgical skill training? J Surg Res. 2000;92(1):53-55.

11. Morris J. Peer assessment: a missing link between teaching and learning? A review of the literature. Nurse Educ Today. 2001;21(7):507-513.

12. Wong JG, Holmboe ES, Huot SJ. Teaching and learning in an 80 -hour work week: A novel day-float rotation for medical residents. $J$ Gen Intern Med. 2004;19(5 Pt 2):519-523.

13. GMC. Tomorrow's Doctors: Recommendations on Undergraduate Medical Education. London: General Medical Council; 2003.

14. Soriano RP, Blatt B, Coplit L, et al. Teaching medical students how to teach: a national survey of students-as-teachers programs in US medical schools. Acad Med. 2010;85(11):1725-1731.

15. Pasquinelli LM, Greenberg LW. A review of medical school programs that train medical students as teachers (MED-SATS). Teach Learn Med. 2008;20(1):73-81.

16. Topping KJ. The effectiveness of peer tutoring in further and higher education: a typology and review of the literature. Higher Education. 1996;32(3):321-345.

17. Whitman NA. Peer teaching: to teach is to learn twice. ASHE-ERIC Higher Education. Washington DC: ERIC Clearinghiudse on Higher Education; 1988.

18. Lockspeiser TM, O’Sullivan P, Teherani A, Muller J. Understanding the experience of being taught by peers: the value of social and cognitive congruence. Adv Health Sci Educ Theory Pract. 2008;13(3): 361-372.

19. Dandavino M, Snell L, Wiseman J. Why medical students should learn how to teach. Med Teach. 2007;29(6):558-565. 
20. Ten Cate O, Durning S. Peer teaching in medical education: twelve reasons to move from theory to practice. Med Teach. 2007;29(6):591-599.

21. Haist SA, Wilson JF, Brigham NL, Fosson SE, Blue AV. Comparing fourth-year medical students with faculty in the teaching of physical examination skills to first-year students. Acad Med. 1998;73(2): 198-200.

22. Kirkpatrick DL. Evaluating Training Programs: The Four Levels. San Francisco, CA: Berrett-Koehler; 1994.

23. Freeth D, Hammick M, Koppel I, et al. A Critical Review of Evaluations of Interprofessional Education. London: Higher Education Academy Learning and Teaching Support Network for Health Sciences and Practice; 2003.

24. Steinert Y, Mann K, Centeno A, et al. A sytematic review of faculty development initiatives designed to improve teaching effectiveness in medical education: BEME guide no. 8. Med Teach. 2006; 28(6):497-526.

25. Batchelder AJ, Rodrigues CM, Lin LY, Hickey PM, Johnson C, Elias JE. The role of students as teachers: four years' experience of a large-scale, peer-led programme. Med Teach. 2010;32(7):547-551.

26. Burke J, Fayaz S, Graham K, Matthew R, Field M. Peer-assisted learning in the acquisition of clinical skills: a supplementary approach to musculoskeletal system training. Med Teach. 2007;29(6):577-582.

27. Graham K, Burke JM, Field M. Undergraduate rheumatology: can peerassisted learning by medical students deliver equivalent training to that provided by specialist staff? Rheumatology (Oxford). 2008;47(5):652-655.

28. Hughes TC, Jiwaji Z, Lally K, et al. Advanced Cardiac Resuscitation Evaluation (ACRE): a randomised single-blind controlled trial of peerled vs. expert-led advanced resuscitation training. Scand J Trauma Resusc Emerg Med. 2010;18:3.

29. Kassab S, Abu-Hijleh MF, Al-Shboul Q, Hamdy H. Student-led tutorials in problem-based learning: educational outcomes and students' perceptions. Med Teach. 2005;27(6):521-526.

30. Hudson JN, Tonkin AL. Clinical skills education: outcomes of relationships between junior medical students, senior peers and simulated patients. Med Educ. 2008;42(9):901-908.

31. Haist SA, Wilson JF, Fosson SE, Brigham NL. Are fourth-year medical students effective teachers of the physical examination to first-year medical students? J Gen Intern Med. 1997;12(3):177-181.

32. Sobral DT. Peer tutoring and student outcomes in a problem-based course. Med Educ. 1994;28(4):284-289.

33. Wong JG, Waldrep TD, Smith TG. Formal peer-teaching in medical school improves academic performance: the MUSC supplemental instructor program. Teach Learn Med. 2007;19(3):216-220.

34. Knobe M, Munker R, Sellei RM, et al. Peer teaching: a randomised controlled trial using student-teachers to teach musculoskeletal ultrasound. Med Educ. 2010;44(2):148-155.

35. Steele DJ, Medder JD, Turner P. A comparison of learning outcomes and attitudes in student- versus faculty-led problem-based learning: an experimental study. Med Educ. 2000;34(1):23-29.
36. Heckmann JG, Dutsch M, Rauch C, Lang C, Weih M, Schwab S. Effects of peer-assisted training during the neurology clerkship: a randomized controlled study. Eur J Neurol. 2008;15(12):1365-1370.

37. Peets $\mathrm{AD}$, Coderre $\mathrm{S}$, Wright $\mathrm{B}$, et al. Involvement in teaching improves learning in medical students: a randomized cross-over study. BMC Med Educ. 2009;9:55.

38. Rengier F, Julian Rauch P, Partovi S, Kirsch J, Nawrotzki R. A threeday anatomy revision course taught by senior peers effectively prepares junior students for their national anatomy exam. Ann Anat. 2010;192(6): 396-399.

39. Weyrich P, Celebi N, Schrauth M, Moltner A, Lammerding-Koppel M, Nikendei C. Peer-assisted versus faculty staff-led skills laboratory training: a randomised controlled trial. Med Educ. 2009;43(2): 113-120.

40. Nestel D, Kidd J. Peer assisted learning in patient-centred interviewing: the impact on student tutors. Med Teach. 2005;27(5):439-444.

41. Tolsgaard MG, Gustafsson A, Rasmussen MB, Hoiby P, Muller CG, Ringsted C. Student teachers can be as good as associate professors in teaching clinical skills. Med Teach. 2007;29(6):553-557.

42. Blatt B, Greenberg L. A multi-level assessment of a program to teach medical students to teach. Adv Health Sci Educ Theory Pract. 2007; 12(1):7-18.

43. Moher D, Schulz KF, Altman DG. Consort. The CONSORT statement: revised recommendations for improving the quality of reports of parallel group randomized trials. BMC Med Res Methodol. 2001;1:2.

44. Smith KL, Petersen DJ, Soriano R, Friedman E, Bensinger LD. Training Tomorrow's Teachers Today: a national medical student teaching and leadership retreat. Med Teach. 2007;29(4):328-334.

45. Fincher RM, Simpson DE, Mennin SP, et al. Scholarship in teaching. An imperative for the 21st century. Acad Med. 2000;75(9): 887-894

46. GMC. The New Doctor: Recommendations on General Clinical Training. London: General Medical Council; 2003.

47. Royal Australasian College of Surgeons. Surgical Competence and Performance: A Guide by The Royal Australasian College of Surgeons. Melbourne, Australia: The Royal Australasian College of Surgeons; 2008.

48. Ziliak ST, McCloskey DN. The Cult of Statistical Significance: How the Standard Error Costs Us Jobs, Justice, and Lives. Ann Arbor, MI: University of Michigan Press; 2008.

49. Davis DA, Mazmanian PE, Fordis M, Van Harrison R, Thorpe KE, Perrier L. Accuracy of physician self-assessment compared with observed measures of competence: a systematic review. JAMA. 2006;296(9):1094-1102.
Advances in Medical Education and Practice

\section{Publish your work in this journal}

Advances in Medical Education and Practice is an international, peerreviewed, open access journal that aims to present and publish research on Medical Education covering medical, dental, nursing and allied healthcare professional education. The journal covers undergraduate education, postgraduate training and continuing medical education

\section{Dovepress}

including emerging trends and innovative models linking education, research, and healthcare services. The manuscript management system is completely online and includes a very quick and fair peer-review system. Visit http://www.dovepress.com/testimonials.php to read real quotes from published authors. 